It seems that the sub-text of McLauglin's work is to rescue anarchism from its reputation for negativity; to show that anarchists have made an important and constructive contribution to political theory and that anarchism has equally important insights to offer to contemporary politics. One of the first things he does in the book is address the anarchists' reputation for violence. In the conclusion, he considers anarchism's social relevance. In these aims, McLaughlin follows a growing line of writers. But the force of the argument is sometimes lost in the exceptionally abstract approach he takes and the lofty tone he tends to adopt. For example, Saul Newman's equally positive contribution to contemporary anarchist theory is inexplicably dismissed before it is discussed (and then only very briefly). At one point, McLaughlin accuses Rorty of dogmatic assertion (p. 84). Yet most of what anarchists are said to believe in the first half of the analysis is almost entirely unsupported. McLaughlin suggests that philosophical rigour is needed to fill the gaps in anarchist thought that historians and political scientists have failed to fill. My impression is that the conclusions McLaughlin finally draws are quite familiar to readers of these literatures.

Ruth Kinna

Loughborough University, Loughborough,

Leicester, UK

\title{
Territory, authority, rights: From medieval to global assemblages
}

\author{
Saskia Sassen \\ Princeton University Press, Princeton, 2006, 493pp., £14.95 paperback, \\ $£ 29.95$ handback; ISBN: 0691095388/978-0 691095387
}

Contemporary Political Theory (2009) 8, 244-248. doi:10.1057/cpt.2008.51

This is primarily a book about globalization, though it also includes an extensive discussion of the historical emergence of the nation-state, making an argument for parallels with the present. Rather than seeing globalization as the decline of the nation-state, Sassen interprets globalization as enacted through changes within the state itself, including the emergence of technical ministries, strengthening of executives and redefinition of state functions. The global is embedded and imbricated in the local and national by means 
such as the state construction of privatized regimes of regulation, the local construction of global cities and financial centres, and the dependence of the city on the concentration of resources in these nodes. So while a fundamental change has happened through globalization - and it has led to the usual effects (interconnectedness, declining national scales and so on) - the picture here is both more complex and differently inflected.

Sassen's method distinguishes between the emergence of specific institutions, techniques and social forms - what she calls 'capabilities' - and the organization of the entire system in a particular way, as an 'organizing logic' or 'foundational' level. She claims that changes at the latter level do not necessarily require new capabilities; they can involve rearticulating existing capabilities into new combinations, and can also result from a cumulative development of capabilities (pp. 6-7). One thus ends up with a rejection of sudden breaks in history; rather, she argues, dramatic changes come about when flows already in operation reach a certain 'tipping point' or 'jump tracks', turning a change in capabilities into a change in organizing logic (pp. 8-9). This account is developed first in relation to the emergence of the nation-state, then in relation to the changes associated with globalization. The elements (logics, capabilities) need to be dislodged from their encasements in historically specific assemblages for their construction and transformations to be examined (p. 5). Capabilities are themselves conditioned by relational systems and hence are social constructs (pp. 7-8), although this fluidity of value choices and structural change can be concealed beneath technical, neutral-sounding language (p. 202).

The book covers a massive historical scope, from the emergence of medieval city-states to the rise of globalization. It does this partly by suggesting similarities in the process of transition to capitalism and to globalization, and partly by making a case for Sassen's interpretive method, which is a variety of complexity-based analysis suggesting the existence of multiple social logics. According to Sassen, 'informal political actors', denied a place in the dominant system, find ways to exercise power outside its formal terms, thereby providing the agency for reconfiguration (p. 71). The excluded make history by constructing new capabilities and logics (pp. 10-12), which can become 'prevalent' before they become 'dominant' (pp. 12, 95), eventually 'tipping' into a new organizing logic (p. 158). Hence the medieval 'burghers' created their own institutions by founding city-states, constructed a 'legal persona' based on rights from this and hence had a crucial role in the origins of capitalism (p. 97). This legal persona empowers capitalists while obscuring conflicts and changes (pp. 190-191); historically it functioned to deny rights to workers and enforce workplace command, although it was later appropriated by workers (pp. 104-105). In the rise of capitalism, furthermore, multiple systems of rule were replaced by exclusive systems; this process is now being 
reversed. This partial disassembling 'denaturalizes what has often unwittingly become naturalized - the national constitution of territory, authority, and rights' (p. 6).

Sassen argues that society as a complex system is inadequately expressed in unduly simplified schemas, which she implicitly associates with most other commentaries on globalization. At a higher level of complexity and detail, the arguments of different approaches are all shown to have a certain validity but without the simplicity of their usual expression. Globalization, Sassen claims, is a new organizing logic with a 'constitutive difference' from what went before; but it is built by drawing on and reconfiguring existing capacities (p. 149). Such capabilities, for instance the IMF, World Bank and GATT/WTO, 'jumped tracks' at the crucial moment of the 1980s (p. 144). The global era is defined by changes in language, legal interpretations and politics (p. 175), such as privatization and a language of efficiency (p. 196). The shift, Sassen suggests, was to some degree a conscious project of the United States (pp. 161-165). Although the global era was qualitatively different from the post-World War II period, America had put the capacities for the global era in place at this time (pp. 165-166). It is not a case of disempowering the state but of embedding global projects within it (p. 30).

Hence, globalization is constructed by and through the state in forms such as rearranged finance ministries and agencies, and the replacement of lawyers with economists in state bureaucracies (pp. 169-171). Privatization is a denationalization of the state (p. 228). But these new capacities also weaken the state in some ways; for instance, one sees a rise of transnational economic arbitration and corporate law separated from states (pp. 234-235). In a more sinister vein, Sassen also draws attention to the growing strength of the executive within states, providing a detailed case study of the American presidency in this regard (pp. 163, 168-185, 210). The new age cannot encompass the liberal state, which is in its last-gasp phase as the distance between state and citizen grows (pp. 319, 410). Meanwhile, as state authority declines, 'raw power' becomes more crucial to the ongoing wave of wars (p. 422).

It also leads to the formation of new assemblages of bits of territory, authority and rights - for example, the global city. Such cities, typified as "partially denationalised strategic territorialisations with considerable regulatory autonomy through the ascendance of private governance regimes' (pp. 54-55), collectively form 'a strategic site for innovations and transformations in multiple institutional domains' (pp. 69-70). Globalization does not simply happen; it relies on the construction of a specific set of institutions to construct and implement it. In this, global cities are crucial. 'Global cities are strategic sites for the combination of resources necessary for the production of these central functions' in system integration (p. 347), operating 
as spatial insertions necessary for globalization as a wider system. This can lead to the emergence of cultures, such as those of financial centres, which are transnational and yet very much specific to particular geographical spaces (pp. 394-395).

On questions of resistance, Sassen describes that analytical borderlands are possible sites of spatial and temporal disruptions (p. 380), and claims that powerlessness is complex because the excluded can make history (p. 321). She emphasizes the role of emergent practices in historical change, but has a rather incomplete picture of what form these practices take today. She discusses the issue briefly in relation to migrants (pp. 295-296, 319), transnational activism (pp. 302-303) and virtual electronic networks (pp. 334-335, 374-376), and refers to an 'informal politics' of everyday urban practices that tend to elude the nation-state (pp. 280-281). She sees these as now exceeding the national scale, linking localities to other localities or to the global level. The account implies these practices are geared towards redefinitions of citizenship and suchlike, rather than the construction of an entire distinct modality of social action; in this, her analysis tends to fall into the 'global civil society' paradigm that views international law and global liberal/social democracy as the solution to globalization, calling for accountability and participation in existing globalized flows (for example pp. 203, 308, 333-334). She seems to assume any reconfiguration will involve broadly the same elements as the other systems she discusses, when in fact it may tend away from the state-form itself. These discussions are shorter and far less nuanced and detailed than her other discussions. One gets the feeling that Sassen is more comfortable analysing the complexities of laws, financial regimes and the composition of state power rather than the different and less 'legible' complexities of informal movements. What if the logic now becoming 'prevalent' is a disruption of territory and authority themselves? What if horizontalism becomes the new 'organizing logic' against the command-logic of capital and the state? In postcolonial theory and contemporary anarchism, the networks of everyday activity are often constructed antagonistically to the global system, as a kind of global logic that is not globalization, rather than a reform impulse. This is an alternative possibility which Sassen does not consider, and which undermines certain of her claims.

Overall, in regard to complexity and the novelty and continuity of globalization, Sassen makes a convincing case for her viewpoint, linking this temporalization of change to an appreciation of the longer duration of some of the 'capabilities' that made it up. On the whole, this is an excellent book, providing a detailed analysis of globalization that largely proves its case. It is not without its difficulties, however. The method at times veers towards eclecticism: Sassen has a fondness for synthesizing different accounts and adopting a 'bit of both' kind of approach, which 
means that it is rare that anything is left out, but at the same time, it is often unclear which forces are driving changes or why they happened one way rather than another. Descriptions of details are sometimes excessive and uneven. The book is somewhat repetitive and longer than it needed to be, and the case for connecting globalization to the historical changes involved in the formation of the nation-state is not really explored. If the aim was to construct something akin to what is done by people such as Hannes Lacher and Arrighi and Silver, it really fails; these provide strong diachronic accounts tracing structures over time, whereas Sassen provides parallels that are at best suggestive. Among other things, an entire historical period, and notably the rise of the welfare state, is largely missing or skimmed over in this account.

In addition, Sassen discusses arrangements of territory, authority and rights (such as regimes of private and corporate law), not the concepts themselves. A reader expecting a Foucauldian genealogy or a deconstruction of the concepts as such will be disappointed; indeed, although specific arrangements of these 'elements' are analysed as complex and constructed, the 'elements' themselves come to seem almost primordial. Another problem is that the level of analysis tends to be very institutional - legal and regulatory changes are covered in minute detail, whereas everyday life, which is certainly given an extensive role, is less well covered. These difficulties aside, the book makes a long but stimulating read for scholars interested in understanding the nuances of institutional and spatial changes involved in globalization, beyond the rhetoric and simplifications. Sassen is truly a force to be reckoned within globalization studies.

Andrew Robinson

The University of Nottingham, University Park, Nottingham, UK

\section{Against recognition}

Lois McNay

Polity Press, Cambridge, 2008, 232pp., £16.99, ISBN: 978-0745629325

Contemporary Political Theory (2009) 8, 248-250. doi:10.1057/cpt.2008.55

Lois McNay's thoughtful and thought-provoking new book Against Recognition deserves to be widely read. Demonstrating an extensive knowledge and perspicacious understanding of contemporary accounts of the psychology 